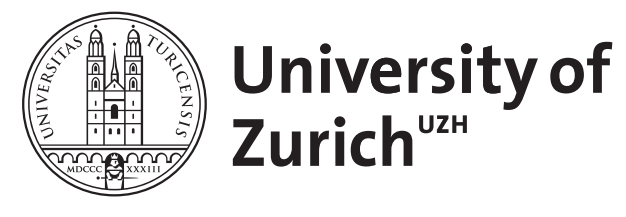

\title{
Actinomyces neuii: Review of an unusual infectious agent
}

\author{
von Graevenitz, A
}

\begin{abstract}
Actinomyces neuii, a species first described in 1994, has proven to be an exception in this genus on account of its aerobic growth, microscopic morphology (no branching), and the types and location of infections. Abscesses and infected atheromas are the most frequent types of infections, followed by infected skin structures, endophthalmitis, and bacteremias, including endocarditis. They are most likely of endogenous origin. To date, approximately 100 cases have been recorded in the literature. Intraabdominal and intrathoracic infections, however, have not yet been described, and cases of classical actinomycosis seem to be extremely rare. Prognosis has generally been good with antibiotic and/or surgical treatment. Susceptibility to antibiotics has paralleled that of other Actinomyces spp.
\end{abstract}

DOI: https://doi.org/10.1007/s15010-011-0088-6

Posted at the Zurich Open Repository and Archive, University of Zurich

ZORA URL: https://doi.org/10.5167/uzh-59717

Journal Article

Published Version

Originally published at:

von Graevenitz, A (2011). Actinomyces neuii: Review of an unusual infectious agent. Infection, 39(2):97100.

DOI: https://doi.org/10.1007/s15010-011-0088-6 


\title{
Actinomyces neuii: review of an unusual infectious agent
}

\author{
Alexander von Graevenitz
}

Received: 27 September 2010/ Accepted: 20 January 2011/Published online: 22 February 2011

(C) Urban \& Vogel 2011

\begin{abstract}
Actinomyces neuii, a species first described in 1994, has proven to be an exception in this genus on account of its aerobic growth, microscopic morphology (no branching), and the types and location of infections. Abscesses and infected atheromas are the most frequent types of infections, followed by infected skin structures, endophthalmitis, and bacteremias, including endocarditis. They are most likely of endogenous origin. To date, approximately 100 cases have been recorded in the literature. Intra-abdominal and intrathoracic infections, however, have not yet been described, and cases of classical actinomycosis seem to be extremely rare. Prognosis has generally been good with antibiotic and/ or surgical treatment. Susceptibility to antibiotics has paralleled that of other Actinomyces spp.
\end{abstract}

\section{Keywords Actinomyces}

\section{History and taxonomy}

Actinomyces spp. are often thought to be the cause of actinomycosis, but they are neither the sole agents of the disease [1] nor do they cause actinomycosis only [2]. In fact, one of the newcomers in this genus, Actinomyces neuii, which will be reviewed here, may not cause classical actinomycosis at all. In 1985, Coudron et al. [3] published

For Gaby Pfyffer's birthday on Oct. 30, 2010.

A. von Graevenitz $(\square)$

Nidelbadstrasse 10, 8028 Kilchberg, Switzerland

e-mail: avg@imm.uzh.ch

A. von Graevenitz

Institute of Medical Microbiology, University of Zurich,

Gloriastrasse 32, 8006 Zurich, Switzerland the characteristics of two aerobically growing coryneform Gram-positive rods isolated from patients with endophthalmitis that resembled organisms earlier called "Coryneform Group A-4" by the Special Bacteriology Reference Laboratory at the Centers for Disease Control (CDC) [4] but differed from this group in several biochemical reactions. Coudron et al. called these and five similar reference strains from the CDC “A-4-like". Two years later, Na'was and CDC researchers [5] published the characteristics of several additional "A-4-like" strains, this time under the term "CDC Fermentative Coryneform Group 1".

In the course of a study aimed at identifying Grampositive rods isolated in the author's laboratory, more such strains were found and investigated using biochemical and chemotaxonomic [6] as well as molecular biological [7] techniques. The results indicated that the Coryneform Group 1 strains did not belong to any of the hitherto known genera of aerobically growing Gram-positive rods but were close to the genera Actinomyces and Arcanobacterium, which are known to grow better under anaerobic or capnophilic conditions than under aerobic ones. 16S rRNA sequence analysis and DNA-DNA hybridization studies as well as cellular and metabolic fatty acid profiles placed these strains as a species in the genus Actinomyces [6, 7], which we named Actinomyces neuii [7] after our colleague Harold Neu, the head of Infectious Disease at Columbia University who had died in 1993 . Two subspecies, A. neuii subsp. neuii and $A$. neuii subsp. anitratus, could be distinguished by biochemical tests [7]. In analogy to the sequestration of the genera Arcanobacterium and Actinobaculum from the genus Actinomyces, suggestions have even been made to create a new genus for $A$. neuii since it has turned out to be closer in sequence similarity [8] and chemotaxonomy [9] to the genera Varibaculum and Mobiluncus than to A. bovis, the type species of Actinomyces. 
We were surprised that within a 4.5-year period, we were able to detect 67 strains of $A$. neuii in our routine diagnostic laboratory [10] even using an identification system which is now obsolete [11]. In our as well as in Clarridge's [12] laboratory $A$. neuii was more frequently isolated than A. odontolyticus, A. israelii, A.meyeri, $A$. viscosus, and $A$. naeslundii. At the time this article was being written, a total of 22 reports of $A$. neuii infections covering approximately 100 cases have been published (some isolates have been listed repeatedly in several publications).

These findings required a change in the concept of Actinomyces as anaerobic or at best aerotolerant organisms, in their role as causative agents of diseases other than classical actinomycosis, and in the frequency of its species isolated in clinical laboratories. As will be also be shown, A. neuii has a microscopic morphology that is unusual for Actinomyces spp, and as an infectious agent it seems to prefer special areas of the human body.

\section{Isolation and identification}

In direct Gram stained preparations and smears from cultures, $A$. neuii appears as a diphtheroidal and even coccoid organism without branching [5, 13-15]. Only one case has been described in which $A$. neuii (not subspeciated) was found as an agent of classical actinomycosis with characteristic Gram-positive filaments and sulfur granules [16]. The diagnosis was based 16S rRNA sequencing but the catalase reaction was negative, a rare trait [13]. Another report mentioned the presence of multinucleated giant cells [17]; however, in the remaining cases only polymorphonuclear leukocytes were found. The sensitivity of direct Gram stains is only approximately $20 \%$ [10]. Biochemical characteristics, among them the positive CAMP reaction, and the identification of $A$. neuii by traditional, semiautomatic , and molecular techniques have been subjects of several publications $[12,14,18]$ and will not be discussed here.

A. neuii grows within $48 \mathrm{~h}$ on aerobically and anaerobically incubated blood agar plates; very few reports mention poorer [19, 20] or better [21] growth under anaerobic conditions. Colonies are indistinguishable from those of other Actinomyces spp., although most resemble the smooth variety of other Actinomyces spp.

\section{Habitat and transmission}

Several Actinomyces spp. are known as colonizers of the human body [22] but to date only one study has shown that A. neuii can be part of the normal flora: DNA-DNA hybridization showed that it was present in larger numbers in patients with gingivitis than in orally healthy individuals [23]. No studies have investigated the presence of $A$. neuii in the environment, but based on the types of infections it must be assumed that it is endogenous. Transmission from patient to patient has also not been observed, with the exception of a case of maternal chorioamnionitis in which A. neuii caused neonatal septicemia (see below).

\section{Infections}

Abscesses and infected atheromas Abscesses and infected atheromas have been, overall, the most frequent infections from which $A$. neuii has been cultured [10, 12, $13,15,17]$. Abscesses were mostly localized in the mammary, axillar, and inguinal areas, similar to other Actinomyces spp. [22]. In a minority of abscesses and atheromas, A. neuii was found in pure culture, with the majority yielding a mixed anaerobic, occasionally also aerobic flora. These mixtures are also not unusual in similar Actinomyces spp. infections [24]. In our own cases, community acquisition was the rule, immunosuppression was rare, and treatment with systemic antimicrobials alone yielded poor results or relapses. The outcome was satisfactory if the infected focus was removed by surgery [10].

Infected skin lesions Infected skin lesions, such as community-acquired diabetic ulcers, were second in frequency in our own collection [10] but have been published elsewhere in single cases only [5, 21]. Mixtures with coagulase-negative staphylococci were the rule.

Endophthalmitis Endophthalmitis following phacoemulsification and lens implantation has been reported in three publications [25-27], although more isolates of $A$. neuii from eyes have been recorded without details [5, 8]. Intraocular, topical, and systemic application of antibiotics led to successful outcomes in two cases [26, 27], while one patient developed a central vein occlusion [25]. Endophthalmitis due to other Actinomyces spp. has been known for some time [28].

Endocarditis Endocarditis has been reported in two patients, one on a prosthetic valve [19] and one complicated by an aortic abscess [29]. The former was cured by antibiotic treatment (penicillin) alone, while the second one required combined medical (ampicillin)-surgical treatment. Other Actinomyces spp. have been known as agents of endocarditis as well [30].

Bacteremia Blood cultures positive for $A$. neuii as the only organism have been reported in 12 patients $[5,10,14$, $31,32]$, excluding those with endocarditis (the Abstract of reference [19] erroneously lists 14 patients with endocarditis). Of the bacteremias whose histories were detailed, 
two originated from the urinary tract [14], one was septicemia in a newborn that had its origin in a maternal chorioamnionitis [31], and one originated from either a urinary tract or a joint infection [10]. All of these were healthcareassociated. With the exception of the latter case, antibiotic treatment was successful. Bacteremias with other Actinomyces spp. have recently been published [33].

Other infections Single cases of pericarditis [34], osteomyelitis (with a mixed culture; [35]), and chorioamnionitis [31] as well as infections of a periprosthetic joint [36], a ventriculo-peritoneal shunt [20], and a penile prosthesis reservoir [37] have been published. We have also observed cases of urinary tract infection and of prostatitis [10]. Similar infections have been caused by other Actinomyces spp. [1, 12, 14, 22, 24]. Removal of prosthetic devices and antibiotics led to successful outcomes.

Of note, no isolates of $A$. neuii have been reported from intra-abdominal and -thoracic sources, which figure prominently in other Actinomyces spp. infections [1, 24]. Of those isolates that were subspeciated, subsp. neuii prevailed over subsp. anitratus. There was no preference for age or sex; and immunocompromised individuals were more frequent only among those with systemic disease and skin lesions. Potential virulence factors have not been investigated thus far.

\section{Antimicrobial susceptibility}

The antimicrobial susceptibility of A. neuii corresponds to that of other Actinomyces spp. [38]. To date, all strains have been susceptible to penicillin, ampicillin, the cephalosporins, imipenem, rifampicin, vancomycin, erythromycin, and clindamycin $[3,10,13,19-21,25,27,29,31,35$, $36]$. A few were resistant to tetracycline $[6,10]$. Susceptibility to aminoglycosides and ciprofloxacin has varied $[10,15,21,25,27,29]$. For treatment, beta-lactam antibiotics and vancomycin have been preferentially used. Development of resistance to the above listed antibiotics has not been observed so far.

Conflict of interest None.

\section{References}

1. Smego RA, Foglia G. Actinomycosis. Clin Infect Dis. 1998;26:1255-63.

2. Sabbe LJM, van de Merve D, Schouls L, Bergmans A, Vaneechoutte M, Vandamme P. Clinical spectrum of infections due to the newly described Actinomyces species turicensis, A. radingae, and A. europaeus. J Clin Microbiol. 1999;37:8-13.

3. Coudron PE, Harris RC, Vaughan MG, Dalton HP. Two similar but atypical strains of Coryneform Group A-4 isolated from patients with endophthalmitis. J Clin Microbiol. 1985;22:475-7.
4. Hollis DG, Weaver RE. Gram-positive organisms: a guide to identification. Centers for Disease Control, Atlanta. 1981.

5. Na'was TE, Hollis DG, Moss CW, Weaver RE. Comparison of biochemical, morphologic, and chemical characteristics of Centers for Disease Control Fermentative Coryneform Groups 1, 2, and A-4. J Clin Microbiol. 1987;25:1354-8.

6. Funke G, Martinetti Lucchini G, Pfyffer GE, Marchiani M, von Graevenitz A. Characteristics of CDC Group 1 and Group 1-like Coryneform Bacteria isolated from clinical specimens. J Clin Microbiol. 1993;31:2907-12.

7. Funke G, Stubbs S, von Graevenitz A, Collins MD. Assignment of human-derived CDC Group 1 Coryneform Bacteria and CDC Group1-like Coryneform Bacteria to the genus Actinomyces as Actinomyces neuii subsp. neuii, sp.nov., subsp.nov., and Actinomyces neuii subsp. anitratus subsp.nov. Int J Syst Bacteriol. 1994:44:167-71.

8. Hoyles L, Collins MD, Falsen E, Nikolaitchouk N, McCartney AL. Transfer of members of the genus Falcivibrio to the genus Mobiluncus and emended description of the genus Mobiluncus. Syst Appl Microbiol. 2004;27:72-83.

9. Schaal KP, Crecelius A, Schumacher G, Yassin AA. Towards a new taxonomic structure of the genus Actinomyces and related bacteria. Nova Acta Leopoldina NF. 1999;80:83-91.

10. Funke G, von Graevenitz A. Infections due to Actinomyces neuii (former "CDC Coryneform Group 1 Bacteria"). Infection. 1995;23:1-3.

11. von Graevenitz A, Funke G. An identification scheme for rapidly and aerobically growing Gram-positive rods. Zentralbl Bakteriol. 1996;284:246-54.

12. Clarridge JE, Zhang Q. Genotypic diversity of clinical Actinomyces species: phenotype, source, and disease correlation among genospecies. J Clin Microbiol. 2002;40:3442-8.

13. Brunner S, Graf S, Riegel P, Altwegg M. Catalase-negative Actinomyces neuii subsp. neuii isolated from an infected mammary prosthesis. Int J Med Microbiol. 2000;290:285-7.

14. Hansen JM, Fjeldsoe-Nielsen H, Sulim S, Kemp M, Christensen JJ. Actinomyces species: a Danish survey on human infections and microbiological characteristics. Open Microbiol J. 2009;3:113-20.

15. Gomez-Garcés JL, Burillo A, Gil Y, Sàez-Nieto J. Soft tissue infections caused by Actinomyces neuii, a rare pathogen. J Clin Microbiol. 2010;48:1508-9.

16. Roustan A, Al Nakib M, Boubli L. Un cas d'actinomycose mammaire primitive à Actinomyces neuii. J Gynecol Obstet Biol Reprod (Paris). 2010;39:64-7.

17. Lacoste C, Escande M-C, Jammet P. Breast Actinomyces neuii abscess simulating primary malignancy: a case diagnosed by fineneedle aspiration. Diagn Cytopathol. 2009;37:311-2.

18. Santala A-M, Sarkonen N, Hall V, Carlson P, Jousimies-Somer $\mathrm{H}$, Könönen E. Evaluation of four commercial test systems for identification of Actinomyces and some closely related species. J Clin Microbiol. 2004;42:418-20.

19. Grundmann S, Huebner J, Stuplich J, Koch A, Wu K, GeibelZehender A, Bode C, Brunner M. Prosthetic valve endocarditis due to Actinomyces neuii successfully treated with antibiotic therapy. J Clin Microbiol. 2010;48:1008-11.

20. Watkins RR, Anthony K, Schroder S, Hall GS. Ventriculoperitoneal shunt infection caused by Actinomyces neuii subsp. neuii. J Clin Microbiol. 2008;46:1888-9.

21. Papaefstathiou K, Sonikian M, Zoumberi M, Arvanitis D, Vlassopoulos D, Kouppari G Actinomyces neuii isolation from foot necrotic ulcer in an immunocompromised patient (Abstract). Clin Microbiol Infect. 2004;10/S.3:404-405.

22. Hall V. Actinomyces - gathering evidence of human colonization and infection. Anaerobe. 2008;14:1-7.

23. Persson GR, Hitti J, Paul K, Hirschi R, Weibel M, Rothen M, Persson RE. Tannerella forsythia and Pseudomonas aeruginosa 
in subgingival bacterial samples from parous women. J Periodontol. 2008;79:508-16.

24. Schaal KP, Lee H-J. Actinomycete infections in humans. Gene. 1992;115:201-11.

25. Garelick JM, Khodabakhsh AJ, Josephberg RG. Acute postoperative endophthalmitis caused by Actinomyces neuii. Am J Ophthalmol. 2002;133:145-7.

26. Pérez-Santonja JJ, Campos-Mollo E, Fuentes-Campos E, Samper-Giménez J, Alio JL. Actinomyces neuii subspecies anitratus chronic endophthalmitis after cataract surgery. Eur J Ophthalmol. 2007;17:1-3.

27. Raman VS, Evans N, Shresta B, Cunningham R. Chronic postoperative endophthalmitis caused by Actinomyces neuii. J Cataract Refract Surg. 2004;30:2641-3.

28. Scarano FJ, Ruddat MS, Robinson A. Actinomyces viscosus postoperative endophthalmitis. Diagn Microbiol Infect Dis. 1999;34:115-7.

29. Cohen E, Bishara J, Medalion B, Sagie A, Garty M. Infective endocarditis due to Actinomyces neuii. Scand J Infect Dis. 2007;17:445-7.

30. Westling K, Lidman C, Thalme A. Tricuspid valve endocarditis caused by a new species of actinomyces: Actinomyces funkei. Scand J Infect Dis. 2002;34:206-7.

31. Mann C, Dertinger S, Hartmann G, Schurz R, Simma B. Actinomyces neuii and neonatal sepsis. Infection. 2002;30:178-80.
32. Ubaldi M, d'Annibale ML, Medori MC, Crotti D. Corinebatterie corineformi: ruolo eziologico in pazienti ospedalizzati e fenotipi di resistenza nel corso di 3 anni di osservazione. Infez Med. 2004;2:126-31.

33. Cone LA, Leung MM, Hirschberg J. Actinomyces odontolyticus bacteremia. Emerg Infect Dis. 2003;9:1629-32.

34. Levy PY, Fournier PE, Charrel R, Metras D, Habib G, Raoult D. Molecular analysis of pericardial fluid: a 7-year experience. Eur Heart J. 2006;27:1942-6.

35. Van Bosterhout B, Boucquey P, Janssens M, Wauters G, Delmée M. Chronic osteomyelitis due to Actinomyces neuii subspecies neuii and Dermabacter hominis. Eur J Clin Microbiol Infect Dis. 2002;21:486-7.

36. Rieber H, Schwarz R, Krämer O, Cordier W, Frommelt L. Actinomyces neuii subsp. neuii associated with periprosthetic infection in total hip arthroplasty as causative agent. J Clin Microbiol. 2009;47:4183-4.

37. His RS, Hotaling JM, Spencer ES, Bollyky PL, Walsh TJ. Isolated infection of a decom-missioned penile prosthesis reservoir with Actinomyces neuii. J Sex Med. 2010. doi:10.1111/j.17436109.2010.02144.x

38. Smith AJ, Hall V, Thakker B, Gemmell CG. Antimicrobial susceptibility testing of Actinomyces species with 12 antimicrobial agents. J Antimicrob Chemother. 2005;56:407-9. 